\title{
A formação pedagógica institucional para a docência na Educação Superior
}

Cláudia Chueire Oliveira ${ }^{1}$

Maura Maria Morita Vasconcellos ${ }^{2}$

OLIVEIRA, C.C.; VASCONCELLOS, M.M.M. The institutional pedagogical development for Higher Education teaching. Interface - Comunic., Saude, Educ., v.15, n.39, p.1011-24, out./dez. 2011.

The paper presents results of a research study related to higher education teaching and pedagogical development. Its objective is to contribute to the development process of teachers who act in higher education, by gathering subsidies for the elaboration of institutional programs. The methodological option was based on the qualitative approach, of an exploratory-descriptive nature; a questionnaire was the data collection instrument, administered to teachers and students from undergraduate courses. The results indicate that the construction of the higher education teaching and the good learning process require institutional, pedagogical and administrative investments, as well as material; the higher education teaching career demands institutional proposals and initiatives which can alter teaching and learning dimensions with a technicalpedagogical support; the quality of education must surpass the one-sidedness of research as instrumentalization for the teaching action; the institutional possibilities and limits reflect choices of professionalization and allow the mapping of epistemological teaching bases in the higher education field.

Keywords: Teacher education. Faculty. Higher education. Professional practice.
Apresentam-se resultados de uma pesquisa sobre docência e formação pedagógica na universidade, visando contribuir para o processo de formação dos docentes que atuam na Educação Superior, colhendo subsídios para a elaboração de programas institucionais. A opção metodológica pautou-se na abordagem de cunho qualitativo, de caráter exploratóriodescritivo. O questionário foi o instrumento para a coleta de dados junto aos docentes e estudantes de cursos de graduação. Os resultados indicam que a construção da docência superior e o ensino de boa qualidade precisam de investimentos institucionais pedagógicos, administrativos e materiais; a carreira docente universitária requer propostas e iniciativas institucionais que alterem dimensões do ensino e da aprendizagem e sua sustentação teóricopedagógica; a qualidade do ensino deve superar o equívoco da unilateralidade da pesquisa como instrumentalização para a ação docente; as possibilidades e limites institucionais refletem escolhas da profissionalização e permitem mapeamento das bases epistemológicas da docência no campo da Educação Superior.

Palavras-chave: Formação de professores. Docentes. Educação Superior. Prática profissional.

\footnotetext{
Relatório de Pesquisa financiada pelo CNPq (Processo 475845/2007), aprovado pelo Comitê de

Ética da Área e Comitê de Ética Envolvendo Seres Humanos.

1,2 Departamento de Educação,

Centro de Educação, Comunicação e Artes, Universidade Estadual de Londrina. Rodovia Celso Garcia Cid - PR 445, Km380. Campus Universitário Londrina, PR, Brasil. 86.051-980 cchueire@uel.br
} 


\section{Introdução}

Este texto, parte integrante de uma pesquisa referente à formação pedagógica de docentes da Educação Superior, pretende colaborar com a construção de um conjunto de conhecimentos peculiares à atuação e à formação pedagógica do docente universitário. A pesquisa realizou-se em dois momentos distintos. Na primeira fase, foram coletadas informações junto aos alunos formandos de vinte e quatro cursos de graduação de uma instituição de Ensino Superior pública estadual (IPES). Na segunda, foram ouvidos os docentes dos mesmos cursos e IPES.

Atuando como professoras de didática na graduação, em disciplinas de formação pedagógica em cursos de especialização e no mestrado em educação, desde a década de 1990, nossas atividades profissionais estão ligadas à formação de professores. A oportunidade de trabalhar com docentes oriundos das mais diversas áreas do conhecimento nos fez perceber a existência de lacunas na formação do professor da Educação Superior.

Martins e Romanowski (2010) são enfáticas ao declararem que a discussão relativa à didática e à formação de professores é urgente neste começo de século. Elas consideram que os "educadoressujeitos", em estudos sobre as práticas de formação, "[...] desenvolvem-se num processo de pesquisaensino que problematiza a prática pedagógica, analisa-a criticamente e propõe novas práticas [...]" (p.61).

Nosso ponto de partida pautou-se, portanto, na esteira do trabalho de Vasconcellos (2005), que, ao abordar a formação pedagógica de docentes de Educação Superior, apresentou indicadores da necessidade de essa formação acontecer de forma mais explicitada e efetiva no interior das instituições educativas.

Com base nesta constatação, entendemos que seria importante conhecer as percepções dos docentes e dos estudantes de graduação a respeito do trabalho docente e da qualidade do ensino vivenciado. Acreditamos que as respostas dos sujeitos podem auxiliar na identificação de necessidades, críticas e sugestões para os processos de formação e atuação do docente de Educação Superior.

\section{A docência na Educação Superior}

As crises do capitalismo que marcaram o século XX agravaram as novas formas de dependência econômica dos países em desenvolvimento para com os organismos internacionais. Entre os produtos oferecidos como tábuas de salvação, a educação das populações apresentou-se como fator importante no conjunto de medidas para a construção de uma nova ordem mundial, visto que, no enquadramento ao templo da globalização, da competitividade e da reestruturação produtiva, poderia ser o meio " [...] capaz de permitir a formação de um trabalhador [para] atender às exigências do mercado" (Maués, 2003, p.90).

A relação social travada entre trabalho e constituição do capitalismo é elemento importante para se compreender a maneira como o homem vem organizando a produção de sua vida material e como tem se caracterizado, para os dias de hoje, o trabalho alienado, uma vez que grande parte dos trabalhadores não possui poder de decisão sobre os processos ou sobre o produto de seu trabalho. Dito de outra forma, a lógica da venda da força de trabalho para outro que detém os meios de produção (capital) estabelece subordinação e dominação nas relações e faz com que o produto do trabalho passe a ser estranho ao trabalhador (Freitas, 1996; 1995).

Estas considerações são necessárias para se situar o papel da educação no mundo capitalista. Falar das relações entre trabalho e educação implica retomar aspectos da acumulação do capital e do desenvolvimento da ciência, da cultura e da formação dos trabalhadores. A exigência de permanente requalificação como condição de trabalho tem resultado na expansão da oferta de cursos superiores de graduação e de pós-graduação. Por sua vez, a influência do Estado mínimo, sobretudo por reduzir a empregabilidade, estimula um afluxo dos profissionais liberais ao exercício da docência na Educação Superior, cuja oferta de emprego apresenta-se em expansão.

Assim, tratar das questões da atuação docente é uma das tarefas da universidade, mas estudos evidenciam que a ação de grande parte dos professores é improvisada, sem qualquer formação 
pedagógica (Pimenta, Anastasiou, 2002). A docência na Educação Superior, notadamente, deixa de considerar características específicas dos cursos, dos estudantes e dos conteúdos. Atuar na Educação Superior significa trilhar uma carreira que é ascendente de acordo com o grau de titulação cada vez maior que lhe é exigido; ensinar, produzir e disseminar conhecimento, entre outras funções complexas que envolvem o mundo universitário. Dessa maneira que é possível o combate à apologia do mercado como instância central e organizadora da vida docente coletiva. Ensinar na Educação Superior significa, literalmente, participar de um processo simultâneo de formação humana discente e docente, em que a adesão ao projeto de consolidação e emancipação intelectual, científica e cultural não se divorcia do mecanismo de produção e socialização deste projeto, visto que o ensinar com qualidade social na Educação Superior agrega, necessariamente, ensino, pesquisa e extensão. Para tanto, consideramos importante destacar que a docência na Educação Superior envolve, em algum momento da carreira profissional, a administração do ensinar e do pesquisar, o que pressupõe atividades que não se improvisam, mas, ao contrário, requerem um diagnóstico e planejamento para atendimento circunstanciado e coerente com as exigências.

Deste modo, compete às universidades assumirem " [...] compromissos institucionais [que criem] espaços e modalidades de discussão, reflexão e análise crítica da atividade docente, com o propósito de assegurar maior qualidade ao ensino de graduação" (Borba, Ferri, Hostins, 2006, p.207). Além disso, é da competência das universidades o ensino superior de boa qualidade para os profissionais que forma, com uma sólida base filosófico-científica, que permita ao sujeito exercer com criticidade seu papel de cidadão.

Diante do exposto, considerar o contexto institucional no qual ocorre o trabalho docente é de extrema importância, já que podemos verificar, no cotidiano da vida universitária, que ainda há uma preocupação com a competência do profissional na sua área de formação, que se manifesta no estímulo da instituição e no aval de seu departamento para a realização de cursos de pós-graduação com ênfase na pesquisa de seu campo de origem. De acordo com Fernandes (1998), o desempenho do professor acaba ficando sem uma reflexão sistematizada que traga sua prática pedagógica como foco de análise.

A preocupação com a qualidade do ensino que o docente oferece à comunidade estudantil ainda não apresenta discussão ampliada. Amaral (2010) afirma que o bom professor é aquele que é pesquisador do seu campo teórico, que compreende a historicidade do processo do conhecimento, mas que também reconhece que a socialização do "arcabouço científico-cultural" (p.27) às novas gerações é sua tarefa primeira, ou seja, ensinar!

Com a ampliação da capacidade de análise e percepção crítica sobre os limites das generalizações/ especificidades do processo de construção do conhecimento científico, "o contexto pode ser o ponto 'concreto' de partida, mas a elaboração do pensamento e o desenvolvimento da capacidade de abstração [...] fundamentais para a apreensão do conhecimento sistematizado" (Ramos, 2003, p.9), reforçam a urgência da discussão.sobre o significado de os professores serem sujeitos de sua própria história, com a grande responsabilidade de serem protagonistas de novos arranjamentos sócio-históricos. Isso só é possível a partir da compreensão da atividade docente como trabalho produzido e que produz relações sociais, transformador da realidade (Oliveira, 2005).

A revisão de literatura, os nossos trabalhos de doutorado e a observação da realidade do ensino no cotidiano das instituições revelaram um panorama que aponta, cada vez mais, para a necessidade de formação pedagógica dos professores de Educação Superior. Trata-se de um requisito essencial para o exercício do magistério superior de boa qualidade. Isaia (2006, p.80) afirma que

[...] as bases para o enfrentamento dos desafios relativos à docência superior pressupõem iniciativas conjuntas de professores e alunos, em consonância com seus contextos institucionais e com as políticas de Educação Superior, a fim de favorecerem o desenvolvimento institucional e profissional de todos aqueles que labutam nesse nível de ensino.

Assumimos, portanto, um conceito de formação docente que implica diagnosticar as necessidades de uma instituição e de sua comunidade e o desenvolvimento de programas e atividades para atenderem a estas necessidades. 
A formação de professores é uma área de investigação e de práticas que, no âmbito da didática e da organização escolar, estuda os processos pelos quais os professores adquirem ou melhoram seus conhecimentos para intervirem profissionalmente no desenvolvimento do seu ensino, do currículo e da instituição (Pachane, 2006). Mesmo assim, vale lembrar a contradição presente neste fato e tão bem explicitada por Dalben (2010, p.166):

Parafraseando Veiga (2009), formar professores é uma aventura [...] Consideramos trabalho docente como uma práxis e, com tal deve ser analisada no contexto da organização escolar. Quando nos lançamos na aventura de formar professores, embora saibamos que seja uma tarefa bastante desafiadora, sabemos que esta tarefa se faz num terreno profundamente vulnerável [...] quando pensamos que formamos docentes para diferentes espaços e contextos.

Sabemos que há aspectos que são importantes "qualidades" que os professores devem possuir, visando proporcionar um "ambiente pedagógico eficaz para diferentes tipos de alunos" (Maués, 2008, p.6). Porém alertamos que, descolado do amparo institucional, produz a ausência ou a insuficiência das condições geradoras de produção de conhecimentos e formação de profissionais qualificados para o magistério superior.

A possibilidade de "[...] superar a ilusão de que as idéias têm por si só o poder de transformação, atuando sobre a consciência dos indivíduos" (Ramos, 2003, p.8) deve-se dar no processo de formação do professor, realizado junto à realidade do seu exercício profissional, das condições de trabalho, do valor atribuído ao conhecimento produzido pela humanidade - para além da redução do conhecimento ao domínio de um conjunto de informações que se destinam à aplicação direta ao seu trabalho, ou seja, além da perspectiva de instruir, fornecer dados, esclarecer e atualizar o professor.

A produção do conhecimento sobre a qualidade do ensino praticado na universidade ainda é um campo novo; e acreditamos que uma das responsabilidades dos profissionais da área da educação é trabalhar em prol da construção de um corpo consistente de conhecimentos, voltados especificamente para a formação do docente de Educação Superior, para que, cada vez mais, as dificuldades relativas a essa formação sejam superadas (Vasconcellos, 2005).

\section{O caminho metodológico do estudo}

O trabalho realizado articulou questões de cunho teórico e empírico, estabelecendo relações e significados que apreendessem especificidades de uma dada situação. Em que pesem os limites inerentes a qualquer tipo de pesquisa, realizamos um estudo com base na análise de depoimentos de docentes e estudantes de graduação, ou seja, sujeitos que também organizam suas experiências e convivem com a prática pedagógica cotidianamente na Educação Superior e em um dado contexto sociocultural. São, portanto, coautores dos processos de ensinar e de aprender na Educação Superior.

Justificamos nossa escolha baseadas em Vasconcellos (2002), que, ao estabelecer critérios para nortear possibilidades de ações transformadoras, expõe sobre a identificação da necessidade de um número significativo de envolvidos em uma instituição. Para o autor, como a necessidade é um produto de interpretação valorativa, indica a possibilidade de transformação decorrente do poder de ação e de recursos disponíveis em dadas circunstâncias.

O questionário foi o instrumento de coleta de dados e de interlocução com os sujeitos que representaram o universo desta investigação. A opção pela utilização de questionários é justificada por Richardson et al. (1999), para quem o questionário, apesar de algumas limitações e de acarretar alguns problemas em relação à devolutiva e confiabilidade, é um instrumento que traz uma série de vantagens em relação a outros. Há a uniformidade da ordem das perguntas e das instruções e, num espaço curto de tempo, obtém informações de um número considerável de pessoas.

Richardson (2007) chama a atenção para os cuidados que o investigador deve ter com as técnicas de pesquisa, uma vez que estas não são elementos neutros, mas, meios para se obterem informações. Minayo (1994, p.14) enfatiza que a ciência social é intrínseca e extrinsecamente ideológica e que "[...] 
toda ciência é comprometida". Sendo assim, está imbuída de interesses e visões de mundo historicamente construídos e pode se submeter ou resistir aos esquemas das políticas de dominação vigentes.

Ao se elaborarem os instrumentos de coleta de dados, é fundamental ter clareza em relação a esta questão para se compreender a relação entre "pesquisador" e "pesquisado", protagonistas de um processo de desenvolvimento (Richardson, 2007, p.19). O autor nos lembra que tanto os questionários como a entrevista não são um fim em si mesmo, mas imprescindíveis instrumentos de coleta, e que utilizá-los de forma adequada é responsabilidade do pesquisador.

O exame da realidade foi por nós compreendido no sentido metodológico da reflexão que se relaciona ao sentido epistemológico, visto que "[...] o cerne do procedimento metodológico diz respeito à construção, no pensamento, do desenvolvimento das contradições presentes na prática, incluindo suas possibilidades de superação" (Freitas, 1995, p.71).

Neste caso, a abordagem de cunho predominantemente qualitativo, de caráter exploratóriodescritivo, foi considerada o caminho mais adequado a trilhar, por privilegiar os significados, as experiências, os motivos, os sentimentos, as atitudes e os valores dos docentes e dos alunos envolvidos com o fenômeno a ser investigado: a docência na Educação Superior em diferentes áreas, qualidades do ensino vivenciado e as possíveis relações com proposições de formação docente, expressão de um " [...] conjunto de expressões humanas constantes nas estruturas, nos processos, nos sujeitos, nos significados e nas representações" (Minayo, 1994, p.15).

Fruto de um trabalho investigativo que reconhece, nos fatos descritos, "símbolos de uma cultura que possui núcleos contraditórios para realizar uma crítica informada sobre eles" (Minayo et al., 2006, p.89), temos plena consciência de que os dados são provisórios, relativos ao conjunto e contexto em questão, todavia, da mesma forma e pelo mesmo motivo, devem ser reconhecidos como importante fonte de informação.

A coleta de dados, mediante um questionário, foi realizada com 64 docentes e 715 alunos de cursos de graduação de uma universidade pública estadual.

O instrumento para os alunos responderem foi formulado com três questões. Na primeira questão, solicitamos que assinalassem a opção (ruim ou péssimo, fraco, razoável, bom, muito bom) que melhor caracterizasse o ensino recebido durante o curso. A segunda questão requereu dos alunos que apontassem os problemas de ensino vivenciados durante o curso. A terceira questão solicitou que apresentassem considerações sobre o que seria um bom ensino na universidade.

Aos docentes, apresentamos o resultado da primeira questão respondida pelos alunos, em gráfico relativo ao curso, e indagamos se os mesmos consideravam existirem problemas de ensino; em caso afirmativo, que explicitassem quais eram. As demais questões aos docentes solicitaram a opinião a respeito da possibilidade de se desenvolverem programas institucionais de formação pedagógica e, ante as respostas positivas, quais poderiam ser os resultados para a melhoria do ensino e da docência.

\section{A realidade investigada em questão}

Um dado que merece destaque, inicialmente, foi a distribuição de setecentos e quarenta questionários aos docentes e a obtenção de apenas 64 respostas de 17 cursos. Consideramos este fato um sintoma bastante expressivo e contraditório. A não-ocupação dos professores de espaços de pesquisa que pretendem ouvir as suas vozes diminui um campo, um tempo e um espaço de possibilidade do registro de suas presença e identidade profissionais.

André (2010, p.278) assevera que, quando se pretende "[...] conhecer mais e melhor os professores e seu trabalho docente [é] porque temos a intenção de descobrir os caminhos mais efetivos para alcançar um ensino de qualidade", o que remete necessariamente a um "trabalho colaborativo entre pesquisadores e professores". Cunha (2010, p.131) também nos auxilia nesta reflexão:

[...] perceber a ação docente como inserida num campo de tensões representa um avanço para as teorias e práticas da formação de professores [...] o exame da construção do campo científico da educação [deve ter] estruturas de conhecimento fundamentais, que farão parte 
dos processos formativos com larga duração. Certamente é a mirada que os atinge e o contexto em que se recontextualizam que trarão formatos distintos e os legitimarão em condições peculiares.

Outros dados são importantes sinalizadores desta investigação. A percepção dos 715 alunos de 24 cursos indica que o ensino recebido foi regular (262 respostas) ou bom (295 respostas). Considerando que a maioria dos estudantes avaliou como bom o ensino recebido, passamos a analisar as respostas obtidas na segunda e terceira questões, que arrolam os motivos que caracterizaram o conceito. Apresentamos alguns depoimentos para, posteriormente, comentá-los:

“Um bom ensino se baseia em: professores qualificados e bem pagos; salas de aula com recursos didáticos variados, investimento em trabalhos de campo de qualidade; investimento em laboratórios onde se possa ver a parte prática do curso". (aluno do curso de Geografia)

"Começando por um efetivo cumprimento dos horários de aula, do conteúdo programático e professores que gostam de ensinar e que conseguem fazer isto, mas esta questão é relativa, depende do aluno também. A universidade deve dar as mínimas condições de estudo aos alunos, por exemplo, silêncio durante as aulas, salas de aula com carteiras decentes e janelas que funcionam". (aluno do curso de Matemática)

"Inicio das disciplinas na data certa, professores em todas as disciplinas, professores e alunos engajados e empenhados". (aluno do curso de Serviço Social)

"Aulas regulares, com professores fixos e capacitados para o trabalho. Recursos físicos disponíveis. Professores que gostem e estejam satisfeitos com o trabalho, pois quem ganha é o aluno". (aluno do curso de Serviço Social)

O bom ensino seria, portanto, para os alunos, aquele que é realizado com base em uma prática de ação sociointelectual, cujo resultado permitiria a intervenção emancipatória dos estudantes na transformação da realidade. As percepções dos alunos indicam um conjunto de ações e decisões que envolvem a disposição dos professores, a conscientização dos alunos e a intervenção institucional. Separadamente, os elementos deste conjunto não se efetivarão em um ensino de boa qualidade social. Poderão demonstrar êxitos parciais, entretanto não farão parte de soluções efetivas. Alguns professores têm a mesma percepção. Exemplificamos:

" $[. .$.$] entendo que existem os seguintes pontos a considerar: a) os alunos aparentemente$ são poucos estimulados no ambiente familiar (visão crítica dos problemas); b) a sociedade tampouco favorece esses estímulos, a despeito da internet, etc. [...] c) com exceção de cursos pedagógicos, os professores universitários são profissionais liberais na posição de professores, sem preparo algum para essa função. Comumente, usam seu 'instinto' para o exercício da docência num mundo com alta comunicação (EAD, etc.), há necessidade de maior preparo para esse exercício". (docente do curso de Engenharia Civil)

"A qualidade não pressupõe apenas os 'problemas de ensino', ainda numa instituição complexa como a universidade brasileira". (docente do curso de Pedagogia)

"Acho que os alunos tratam o problema da falta de docente como qualidade do curso. O Design Gráfico foi criticado sem considerar a necessidade de docentes específicos por estratégias políticas e desde sua criação tem sofrido com um rodízio de docentes temporários, a sua maioria de 20 horas. No ano de 2008 teve turma que ficou sem professor até julho e disciplinas que tiveram três docentes e isso afeta e muito a qualidade do curso". (docente do curso de Design Gráfico) 
"Os dados parecem revelar o bom aproveitamento do curso apesar da falta de espaço físico adequado [...] e no caso do curso de Artes Cênicas o espaço físico é co-autor no processo de trabalho desenvolvido, certamente que nossos estudantes apontam tal falta que revela um problema de ensino". (docente do curso de Artes Cênicas)

Os depoimentos registrados nas questões iniciais, ou seja, a qualidade do ensino que se vivencia, remetem-nos a uma discussão, neste artigo, de dois aspectos: a disposição para a docência e a atuação institucional na docência.

De acordo com as manifestações dos sujeitos (alunos e professores), alguns docentes não estão "preparados" para o exercício do magistério. Um aluno do curso de Química considera que:

"O bom ensino em uma universidade consiste na contratação de verdadeiros docentes, ou seja, professores. Acredito que uma separação entre professor e pesquisador deveria ser feita, pois há muitos pesquisadores que não gostam de ministrar aulas, logo os alunos que arcam com as conseqüências de uma aula ruim".

A declaração de um docente do curso de ciências sociais referenda a expressão do aluno ao afirmar que há

"[...] falta de entrosamento entre os docentes, desconhecimento do PPP [Projeto Político Pedagógico], desprezo pela habilitação em licenciatura [...]".

O sentido da função "ensinar" requer a aquisição de conhecimentos pedagógicos, aqueles que tratam de princípios fundamentais de organização do trabalho docente, tais como políticas educacionais, sistemas curriculares, comunicação na situação de ensino, planejamento de ensino, avaliação da aprendizagem, entre outros. Bazzo (2008) apresenta indicações de promoções institucionais em programas de formação docente que são esclarecedoras do conjunto de ações e decisões necessárias ao bom ensino na Educação Superior. De acordo com a autora,

[...] poderiam ser objeto de estudos e pesquisas desde as discussões dos projetos pedagógicos de cada curso até questões percebidas com merecedoras de maior reflexão nos processos de avaliação institucional, hoje instalados em todas as universidades brasileiras em atendimento ao que determina o programa SINAES [Sistema Nacional de Avaliação da Educação Superior]. Essas atividades seriam permanentemente acompanhadas pelos próprios professores, bem como pelos alunos e pela instituição nos seus diversos níveis e empreendimentos avaliativos, sempre, porém, de características diagnósticas e emancipatórias. Nesse processo, poder-se-ia esperar, em médio prazo, que o professor, ao perceber a importância do seu papel na tarefa educativa dos jovens para além da técnica e do domínio dos conteúdos específicos, fique cada vez mais envolvido pelas questões da educação e da real aprendizagem/formação de seus alunos, de tal sorte que, na mesma medida da importância que dá às pesquisas de sua área específica de conhecimento, engajese na investigação e na descoberta de novas e desafiantes maneiras de desenvolver o ensino. (Bazzo, 2008, p.12)

Os cursos de pós-graduação têm sido o principal veículo de preparação do docente de Educação Superior. Muitas vezes, porém, não há a formação para a docência. Não se questionam, nem nos editais de concursos nem no cotidiano das instituições, elementos que indiquem que o profissional que domina uma área de conhecimento seja capaz também de realizar a transposição didática necessária a um bom ensino. Como descrevem Pimenta e Anastasiou (2002, p.142-3):

Institucionalmente, uma vez aprovado no concurso ou contratado, o professor recebe uma ementa, um plano de ensino do ano anterior e, com isso em mãos, o horário de trabalho que 
Ihe cabe desempenhar. A partir daí, as questões de sala de aula, de aprendizagem e de ensino, de metodologia e de avaliação são de sua responsabilidade, [...]. Ou seja, reforça-se aí o processo de trabalho solitário, extremamente individual e individualizado; o professor é deixado à sua própria sorte e, se for bastante prudente, evitará situações extremas nas quais fiquem patentes as falhas de seu desempenho.

A formação em cursos stricto sensu tem priorizado as atividades de pesquisa e as associa, com frequência, à essência direta do trabalho docente. A introdução de estágios de docência é uma alternativa interessante, a título de introdução aos pressupostos de formação do corpo docente superior, todavia requer que a discussão do significado de tais experiências seja efetivada como uma relação orgânica de todas as etapas do processo de ensinar e aprender e com os diferentes sujeitos envolvidos (Bazzo, 2008). Porém não podem ser vivências únicas e exclusivas de formação, há que se buscar por formatos mais expressivos de inclusão de processos formativos iniciais e continuados.

Vale destacar que processos mais expressivos de formação do docente superior requerem a administração negociada entre as partes. Oportunidades de cooptação podem ser propostas com roupagens que favoreçam o negligenciar das restrições de tempo real de trabalho, as condições de efetivo exercício do magistério e as necessidades pedagógicas da docência superior que abrangem o aluno, o professor e o conteúdo a ser desenvolvido. Em outras palavras, os processos formativos não podem ceder aos moldes de conveniências econômicas, que requisitam o docente como colaborador na consecução de padrões mercadológicos e de produtividade para a Educação Superior, que apelam para parcerias que se destinam a um pseudodesenvolvimento profissional e que trazem mais intensificação do trabalho docente. Como exemplo, podemos destacar um excerto, já citado, das manifestações dos alunos que admitem o bom ensino permeado por "[...] efetivo cumprimento dos horários de aula, do conteúdo programático e professores que gostam de ensinar e que conseguem fazer isto" (aluno do curso de Matemática). Docentes que "conseguem ensinar" na Educação Superior fazem parte de um grupo de profissionais que admitem: o planejamento, a preparação das aulas, o estudo dos temas, a organização do ambiente de ensino e de aprendizagem, a proposição de ações críticas e inovadoras, entre outras, em um conjunto de tensões de diversidades e de demandas acadêmicas.

Outro aspecto evidenciado pelos depoimentos de alunos e professores diz respeito ao envolvimento das instituições de Ensino Superior (IES) na docência. São consideradas desde a organização pedagógica dos cursos até as condições materiais das estruturas físicas. Para os alunos que colaboraram com esta investigação, é importante que haja "[...] professores bem preparados e que tenham didática para dar aula [e] laboratórios para desenvolvimento das atividades". (aluno do curso de Ciência da Computação)

Um docente do curso de química assim se manifesta: " [...] as condições de ensino poderiam ser ainda melhores. Como por exemplo: mais materiais no laboratório, técnicos mais bem preparados e com melhor boa vontade para preparar as aulas". Já um docente do curso de Agronomia afirma: "É lógico também que cursos pedagógicos de formação ajudariam muito na reciclagem dos professores, vejo isso, pois também atuo no ensino médio onde os professores recebem este tipo de formação".

A criação de um ambiente pedagógico favorecedor da aprendizagem deve considerar a superação de três grandes problemas: corpo docente em efetivo exercício profissional; espaços e estruturas físicas compatíveis com as necessidades dos cursos, e acompanhamento e avaliação institucional dos processos pedagógicos vivenciados. Transcrevemos, a seguir, mais alguns dos depoimentos dos sujeitos que exemplificam as situações destacadas:

“Falta de materiais decentes para as aulas práticas e técnicos mal preparados para ajudar. Professores (alguns) péssimos, que não deveriam estar dando aula dentro de uma universidade tão grande". (aluno do curso de Química)

"Falta de professores, muita troca de professor em uma disciplina, atraso para início da disciplina (disciplina anual que as aulas iniciaram em setembro)". (aluno do curso de Serviço Social) 
"Muitos docentes passam nos concursos (efetivos e/ou temporários) tendo pouca ou nenhuma experiência prática. Quando vão atuar não sabem relacionar seu conteúdo com o cotidiano real. Ficam muito preocupados em formar pesquisadores e esquecem de formar profissionais". (docente do curso de Educação Física)

"A falta de preparo se confunde com o desânimo do docente, desânimo pelo baixo salário ou pela falta de perspectiva profissional, ambos aspectos são culpa do governo e da desorganização/descaso para com a educação brasileira. Política e Educação não combinam". (aluno do curso de Ciências da Computação)

"Falta de professores para algumas disciplinas, professores sem didática, materiais desatualizados, falta de alguns livros na biblioteca". (aluno do curso de Administração)

"Creio que temos problemas de ensino em Engenharia Civil porque a maioria absoluta dos docentes não teve formação para ensino profissional". (docente do curso de Engenharia Civil)

As condições das estruturas físicas, dos ambientes de ensino e aprendizagem, das motivações e contratação docente aparecem como sendo precárias, desatualizadas, insuficientes e, até mesmo, incompatíveis com uma proposta pedagógica de formação de profissionais em nível superior. Isaia e Bolzan (2007, p.174) consideram que a realidade de muitas IES está distante de uma " [...] política consistente, sistemática e organizada, que leve em conta as peculiaridades de cada domínio e do contexto institucional concreto para o qual se orienta", ou seja, os processos formativos profissionais, entre os quais deveriam estar, inclusive, aqueles direcionados aos professores.

É importante trazer para o debate, portanto, a opinião dos docentes relativa aos processos de formação. A maioria dos docentes participantes (42 professores) é favorável ao desenvolvimento de programas institucionais de formação pedagógica. Aqueles que não são favoráveis indicam que os problemas não são de ordem didática ou pedagógica, mas de dedicação de professores e alunos.

Os argumentos dos docentes que apoiam a ideia dos programas de formação institucional remetem a muitos pontos, entre eles: a inserção do professor no espaço universitário, o reconhecimento de metodologias de ensino mais apropriadas ao curso, discussão ampliada da função social da universidade, processo de avaliação da aprendizagem, acompanhamento pedagógico das reformulações dos projetos pedagógicos dos cursos etc. Apresentamos algumas manifestações:

"Sinto-me totalmente desamparada em relação a minha formação e do exigido pelas IES. Tudo fica por conta do professor: trabalhar com novas tecnologias, trabalhar as diferenças em sala de aula, entender as dificuldades dos estudantes, mesmo que estas estejam muito além da incumbência do professor. Além disto, o professor tem que desenvolver projetos, participar de comissão, ter uma carga horária didática muito acima dos existentes em instituições bem conceituadas do país. Enfim, penso que se exige muito do professor e muito pouco (quase nada) é dado para a execução das exigências. Sem contar a falta de infra-estrutura. Como trabalhar em laboratórios de informática se não tem técnicos e/ou monitores que nos auxiliem. Como ter um "bom" método de avaliação numa sala com 60, 80 estudantes. Como trabalhar em sala o desinteresse dos estudantes. Como trabalhar a falta de conteúdo matemático que vem se acumulando desde a alfabetização. Como dar aulas numa universidade em construção com marretas, brocas, martelos o ano todo na cabeça do professor e do estudante. Como exercer, de fato, a profissão de professor se a maior parte do tempo ficamos envolvidos em imbróglios administrativos, burocráticos e políticos. Que programa desenvolver eu não sei". (docente do curso de Matemática)

“Programas relativos a orientação pedagógica do professor, para trabalhar com as aulas/ alunos. Muitas vezes o docente domina a teoria (principalmente no âmbito da psicologia) / 
prática, mas tem muita dificuldade na transmissão dos conteúdos". (docente do curso de Psicologia)

"Os resultados são em longo prazo, acho importante uma formação integral que envolva prática de ensino, formas de levar o conhecimento ao aluno que o faça participar mais, avaliação, entre outros. Somente melhoraremos o ensino se o professor conseguir controlar efetivamente todas as etapas do ensino-aprendizagem". (docente do curso de Agronomia)

"Didática, metodologias de ensino, uso de novas tecnologias de ensino em sala de aula, tanto para professores quanto para alunos". (docente do curso de História)

"Talvez um levantamento das inovações adotadas pelos docentes e que estão trazendo resultados positivos e que estejam cristalizadas por pesquisas e não pelo 'achismo'". (docente do curso de Matemática)

As manifestações dos docentes nos remetem à discussão de que é preciso que a universidade reconheça a importância do trabalho docente na difusão do conhecimento por meio da pesquisa, mas que dê a mesma importância à docência. Lüdke $(2005$, p.12) utiliza uma expressão muito interessante, a "invisibilidade docente", para tratar da formação de professores, e considera que,

Rompendo com a invisibilidade do trabalho docente, desenvolvem um programa unindo saber e ação na atuação do professor, que assume também o papel de pesquisador [...] centrar-se na situação de trabalho seria condição e garantia de uma pesquisa produtiva e com sentido [...] rompendo com a separação hierárquica entre o pesquisador e o professor.

Trouxemos, novamente, o binômio ensino-pesquisa, considerando que, para que não haja desvinculação, os programas de formação não podem se resumir a eventos isolados e pontuais. Acreditamos que os programas de formação docente devem ser articulados à pesquisa, à produção acadêmica que é desenvolvida na universidade.

A indicação de problemas institucionais é consequência de um rol de propostas de "obrigação de resultados", que hoje é imposta ao professor e que não considera, muitas vezes, as questões estruturais das IES, tais como: condições de trabalho, turmas com número excessivo de alunos, ausência de política de valorização do magistério, entre outras. São condições que incidem sobre o trabalho docente, tornando-o precário, e correspondem ao discurso hegemônico da mercantilização do conhecimento como princípio da excelência (Maués, 2008).

Os docentes têm sido alvo do produtivismo acadêmico instalado nas políticas e ações direcionadas à Educação Superior. Desse modo é considerado

[...] "competente" aquele docente que consegue cumprir as exigências das agências de fomento, ou seja aprovando projetos de pesquisa, solicitações de financiamento de participação em eventos e tantos outros indicadores estabelecidos a partir da lógica mercantilista. (Maués, 2008, p.10)

Tal pensamento altera a natureza da docência, por retirar a importância de um conjunto de ações que gere formação ética nos alunos, que manifeste interações de boa qualidade entre os pares professor-aluno e aluno-aluno, que favoreça clareza, organização e adequação das linguagens usadas nas aulas, que garanta aprofundamento nas especificidades do ensino de cada área do conhecimento. Em outras palavras, o domínio do conhecimento expressado na situação de ensino requer o trato com os três elementos didático-pedagógicos: aluno, conteúdo e professor, para além da metodologia específica de uma área da pesquisa. Trata-se, conforme nos indicam Borba, Ferri e Hostins (2006), de um compromisso social de base ético-política óbvia. 
A ausência de responsabilização institucional sobre a docência superior tem transformado o professor

[...] em empreendedor que precisa ser capaz de celebrar, por meio da instituição, convênios, atrair empresas que se interessem em financiar suas pesquisas e montar seus laboratórios, transformando-se assim em pessoas quase jurídicas que conseguem realizar "negócios" que vão tornar a instituição mais competitiva. Isso representa uma intensificação do trabalho, na medida em que exige mais tempo desse profissional, muitas vezes tendo que estender a jornada de trabalho para além das oito horas, a fim de poder realizar todas essas atividades que agora são dele esperadas. (Maués, 2008, p.11)

Neste momento, vale a pena lembrar que a Constituição da República Federativa do Brasil de 1988 (Brasil, 1994), quando trata sobre as questões que envolvem a educação nacional (Capítulo III - da Educação, da Cultura e do Desporto, seção 1 - Da Educação), estabelece como princípio, entre outros, a "valorização dos profissionais do ensino" (art. 206, V) e a "garantia de padrão de qualidade" (art. 206, VII) para o ensino. Mais recentemente, na forma da Lei 9.394, de 20 de dezembro de 1996, as diretrizes e bases da educação nacional foram materializadas e acrescentadas de Portarias, Decretos e Resoluções que trazem regulamentações mais ordinárias.

Enricone (2007) postula que os problemas da prática educacional de nível superior não podem continuar a se resumir a "problemas meramente instrucionais" (p.151), ao contrário, devem ser objeto de ações e discussões que envolvam "uma mudança simbólica em movimento" (p.155), considerando o modo como a "dimensão profissional do docente universitário tem a ver com o funcionamento de políticas de administração" (p.156) nos níveis pedagógico, pessoal e institucional. Para a autora, qualquer modalidade de educação universitária de professores deve " [...] partir das intenções e dos valores do presente e orientar-se para as expectativas do futuro, que nunca está determinado, ainda que dependa das possibilidades entre as alternativas agora existentes" (p.157).

O trabalho do docente universitário - enquanto combinação de demandas complexas que envolvem o ensino, a pesquisa, a extensão, a pesquisa do ensino, o ensino para a pesquisa, a extensão como socialização etc. - com frequência, não encontra os princípios constitucionais e os decorrentes legais assegurados nas IES.

\section{Algumas considerações}

A título de apresentar algumas ideias conclusivas, lembramos que nossa investigação junto aos professores e alunos permitiu reforçar a questão de que a carreira docente universitária requer que sejam apresentadas propostas pelas IES cujas iniciativas alterem dimensões do ensino e da aprendizagem com argumentação/sustentação teórico-pedagógica.

Ao docente, profissional da educação, compete: participar na elaboração dos projetos pedagógicos dos cursos, zelar pela condução do processo de ensino que vise à aprendizagem dos alunos, produzir conhecimentos e disseminá-los como um bem da humanidade, entre outras atribuições. É necessário, portanto, que, na administração da vida universitária, sua carreira docente também seja incluída.

Se, por um lado, os estudos na área já apontam necessidades de programas institucionais que amparem o exercício no magistério superior, por outro lado, ainda é perceptível o equívoco da unilateralidade da pesquisa como instrumentalização para a ação docente. As necessidades formativas dos docentes da Educação Superior têm complexidade ímpar, em especial pela consideração de que o processo de formação iniciou-se, mesmo que não intencionalmente, quando aluno dos cursos de graduação. Assim, a superação/manutenção de modelos de ordem didático-pedagógicos refere-se a um conjunto de ações de investigação, análise e discussão de práticas pedagógicas institucionalizadas, como recursos importantes para o planejamento não só de ensino, mas, também, dos sistemas educativos superiores.

Além disso, quaisquer que sejam as iniciativas institucionais, uma análise mais rigorosa da qualidade do ensino vivenciado por docentes deve partir da construção das experiências já vivenciadas pelos sujeitos, um marco que permita ser uma espécie de referência sistemática dos investimentos pessoais, 
pedagógicos, materiais, administrativos. O campo do conhecimento tratado na forma de conteúdo de ensino, as concepções e valores atribuídos à prática pedagógica cotidiana precisam ser considerados como elementos fundamentais de formação docente, os quais são tão necessários quanto a pesquisa na área específica.

Lembramos, ainda, que as condições materiais e objetivas do trabalho docente são aspectos fundamentais para o desenvolvimento da Educação Superior de boa qualidade. Mais do que um incentivo a um investimento de envergadura maciça, trata-se de mostrar, para a sociedade, a importância da formação do docente que irá formar outros tantos profissionais, muitos deles docentes também. Apesar de dificilmente percebida por esta sociedade, a importância reside em ações prioritárias para a própria vida do homem. O cidadão, que vive em um tempo em que o desmantelamento das estruturas sociais luta arduamente para manter a hegemonia capitalista dominadora, precisa reconhecer, no docente do ensino superior, uma classe de trabalhadores que enfrenta precarização nas relações e condições de trabalho. $O$ aligeiramento das formações, a expansão desordenada de cursos superiores, a ausência de estruturas físicas compatíveis com a produção da ciência são, juntamente com o tempo disponibilizado, alguns dos exemplos de condições materiais que precisam ser repensadas. Os recursos destinados ao ensino perecem diante daqueles dirigidos à pesquisa, levando à diminuição da resistência da cultura instalada do alto desempenho produtivo.

O foco no valor central das possibilidades e limites institucionais poderá ser avistado na superação dos problemas, irá refletir nas escolhas e nas tomadas de decisão do objeto de trabalho da profissionalização em nível superior - produzido e atualizado com a pesquisa - e permitirá o mapeamento das bases epistemológicas da docência no campo da Educação Superior. A empreitada de uma Educação Superior de qualidade requer a absoluta prioridade da ordem política, do caráter organizativo e produtivo da ciência e da cultura, e da ação humana participativa na construção social.

\section{Colaboradores}

Os autores trabalharam juntos em todas as etapas de produção do manuscrito.

\section{Referências}

AMARAL, A.L. Significados e contradições nos processos de formação de professores. In: DALBEN, A.I.L.F. et al. (Orgs.). Convergências e tensões no campo da formação e do trabalho docente. Belo Horizonte: Autêntica, 2010. p.24-46.

ANDRÉ, M. A pesquisa sobre formação de professores: contribuições à delimitação do campo. In: DALBEN, A.I.L.F. et al. (Orgs.). Convergências e tensões no campo da formação e do trabalho docente. Belo Horizonte: Autêntica, 2010. p.273-87.

BAZZO, V.L. Constituição da profissionalidade docente na educação superior: apontamentos para uma política nacional de formação. In: REUNIÃO ANUAL DA ANPED, 30., 2008, Poços de Caldas. Anais... Poços de Caldas, 2008. Disponível em: <http://www.anped.org.br/reunioes./31ra/1trabalho/GT11-4842-Int.pdf > . Acesso em: 7 mar. 2010.

BORBA, A.M.; FERRI, C.; HOSTINS, R.C.L. Formação continuada de professores 
universitários: alguns enfrentamentos necessários. In: RISTOF, D.; SAVEGNANI, P. (Orgs.). Docência na Educação Superior. Brasília: Instituto Nacional de Pesquisas Educacionais Anísio Teixeira, 2006. v.5. p.203-15 (Coleção Educação Superior em Debate).

BRASIL. Câmara dos Deputados. Constituição da República Federativa do Brasil (1988). Brasília: Coordenação de Publicações da Câmara dos Deputados, 1994.

CUNHA, M.I. Lugares de formação: tensões entre a academia e o trabalho docente. In: DALBEN, A.I.L.F. et al. (Orgs.). Convergências e tensões no campo da formação e do trabalho docente. Belo Horizonte: Autêntica, 2010. p.129-49.

DALBEN, A.I.L.F. Tensões entre formação e docência: buscas pelos acertos de um trabalho. In: DALBEN, A.I.L.F. et al. (Orgs.). Convergências e tensões no campo da formação e do trabalho docente. Belo Horizonte: Autêntica, 2010. p.166-87.

ENRICONE, D. A universidade e a aprendizagem da docência. In: CUNHA, M.I. (Org.). Reflexões e práticas em pedagogia universitária. Campinas: Papirus, 2007. p.145-59.

FERNANDES, C.M.B. Formação do professor universitário: tarefa de quem? In: MASETTO, M.T. (Org.). Docência na universidade. Campinas: Papirus, 1998. p.95-112.

FREITAS, H.C.L. O trabalho como princípio articulador na prática de ensino e nos estágios. Campinas: Papirus, 1996.

FREITAS, L.C. Crítica da organização do trabalho pedagógico e da didática. Campinas: Papirus, 1995.

ISAIA, S.M. Desafios à docência superior: pressupostos a considerar. In: RISTOF, D.; SAVEGNANI, P. (Orgs.). Docência na Educação Superior. Brasília: Instituto Nacional de Pesquisas Educacionais Anísio Teixeira, 2006. v.5. p.63-84. (Coleção Educação Superior em Debate).

ISAIA, S.M.A.; BOLZAN, D.P.V. Construção da profissão docente/professoralidade em debate: desafios para a Educação Superior. In: CUNHA, M.I. (Org.). Reflexões e práticas em pedagogia universitária. Campinas: Papirus, 2007. p.11-26.

LÜDKE, M. Pesquisa e formação docente. Cad. Pesqui., v.35, n.125, p.11-2, 2005.

MARTINS, P.L.O.; ROMANOWSKI, J.P. A didática na formação pedagógica de professores nas novas propostas para os cursos de licenciaturas. In: DALBEN, A.I.L.F. et al. (Orgs.). Convergências e tensões no campo da formação e do trabalho docente. Belo Horizonte: Autêntica, 2010. p.61-80.

MAUÉS, O.C. Reformas internacionais da educação e formação de professores. Cad. Pesqu., n.118, p.89-118, 2003. Disponível em: <http://www.scielo.br/scielo.php? script $=$ sci_arttext $\&$ pid $=s 0100-157420030001000005 \& I m g=p t \& n r m=i s o>$. Acesso em: 5 maio 2010.

A política de Educação Superior para a formação e o trabalho docente: a nova regulação educacional. In: REUNIÃO ANUAL DA ANPED, 30., 2008, Poços de Caldas. Anais... Poços de Caldas, 2008. Disponível em: <http://www.anped.org.br/reunioes./ 31ra/1trabalho/GT11-3974-Int.pdf>. Acesso em: 7 mar. 2010.

MINAYO, M.C.S. Ciência, técnica e arte: o desafio da pesquisa social. In: Pesquisa social: teoria, método e criatividade. Petrópolis: Vozes, 1994. p.9-29. (Org.)

MINAYO, M.C.S.; ASSIS, S.G.; SOUZA, E.R. (Orgs.). Avaliação por triangulação de métodos: abordagens de programas sociais. Rio de Janeiro: Fiocruz, 2006.

OLIVEIRA, C.C. A formação superior de professores através de mídias interativas. 2005. Tese (Doutorado) - Faculdade de educação, Universidade Estadual de Campinas, Campinas. 2005. 
PACHANE, G.G. Teoria e prática na formação de professores universitários: elementos para discussão. In: RISTOF, D.; SAVEGNANI, P. (Orgs.). Docência na Educação Superior. Brasília: Instituto Nacional de Pesquisas Educacionais Anísio Teixeira, 2006. v.5.

p.97-146. (Coleção Educação Superior em Debate).

PIMENTA, S.G.; ANASTASIOU, L.G.C. Docência no ensino superior. São Paulo: Cortez, 2002.

RAMOS, M.N. A contextualização no currículo de ensino médio: a necessidade da crítica na construção do saber científico. Rev. Ensino Médio, v.1, n.3, p.9-12, 2003.

RICHARDSON, R.J. et al. Pesquisa social: métodos e técnicas. São Paulo: Atlas, 1999.

VASCONCELLOS, C.S. Coordenação do trabalho pedagógico: do projeto político-pedagógico ao cotidiano da sala de aula. São Paulo: Libertad, 2002.

VASCONCELLOS, M.M.M. Desafios da formação do docente universitário. 2005. Tese (Doutorado) - Faculdade de Educação, Universidade Estadual de Campinas, Campinas. 2005.

OLIVEIRA, C.C.; VASCONCELLOS, M.M.M. La formación pedagógica institucional para la docencia en la Enseñanza Superior. Interface - Comunic., Saude, Educ., v.15, n.39, p.1011-24, out./dez. 2011.

El texto presenta resultados de pesquisa relativa a docencia y formación pedagógica en la universidad. El objetivo fue contribuir para el proceso de formación de docentes que actúan en enseñanza superior, recogiendo subsidios para la elaboración de programas institucionales. La opción metodológica fue el planteamiento cualitativo, exploratorio descriptivo. El cuestionario fue usado para colectar datos junto a los docentes y estudiantes de cursos de graduación. Los resultados indican que la construcción de la docencia superior y la enseñanza de buena calidad necesitan inversiones institucionales pedagógicas, administrativas y materiales; la carrera docente requiere propuestas e iniciativas institucionales que alteren dimensiones de la enseñanza y aprendizaje con sustentación teórico-pedagógica; su calidad debe superar el equívoco de la unilateralidad de la pesquisa como instrumentación para la acción docente; las posibilidades y límites institucionales reflejan la selección de la profesionalización y permiten el mapear de las bases epistemológicas de la docencia en la universidad.

Palabras clave: Formación de profesores. Docentes. Enseñanza superior. Práctica profesional. 